\title{
Characterization and Photoactivity of Cotton Loaded with ZnO NPs
}

\author{
A. A. Owis'1, M. Y. F. Elzayat1, T. A. Abdel-Baset1,2* \\ ${ }^{1}$ Department of Physics, Faculty of Science, Fayoum University, El Fayoum, Egypt \\ ${ }^{2}$ Physics Department, Faculty of Science, Taibah University, Yanbu, Saudi Arabia \\ Email: ^taa03@fayoum.edu.eg
}

How to cite this paper: Owis, A.A., Elzayat, M.Y.F. and Abdel-Baset, T.A. (2020) Characterization and Photoactivity of Cotton Loaded with ZnO NPs. Open Journal of Applied Sciences, 10, 111-117. https://doi.org/10.4236/ojapps.2020.104009

Received: February 8, 2020

Accepted: April 6, 2020

Published: April 9, 2020

Copyright (C) 2020 by author(s) and Scientific Research Publishing Inc. This work is licensed under the Creative Commons Attribution International License (CC BY 4.0).

http://creativecommons.org/licenses/by/4.0/

\section{(c) (i) Open Access}

\begin{abstract}
In this work, $\mathrm{ZnO}$ NPs were prepared by a simple co-precipitation technique. Cotton fibers loaded with $\mathrm{ZnO}$ NPs were prepared also. X-ray diffraction (XRD), scanning electron microscopy (SEM) and UV-Vis spectrophotometer have been used to characterize the prepared samples. The photocatalytic properties of the cotton loaded with $\mathrm{ZnO}(\mathrm{C}-\mathrm{ZnO})$ and $\mathrm{ZnO} \mathrm{NPs}$, were studied under sunlight irradiation and lamp illumination as a function on time. The results showed that X-ray diffraction of $\mathrm{ZnO}$ NPs has a single-phase wurtzite structure with an average particle size of $29 \mathrm{~nm}$. The morphology on the surface of ZnO NPs has a spherical shape. The optical band gap of $\mathrm{ZnO}$ nanoparticles was $3.37 \mathrm{eV}$. The photocatalytic confirms that $\mathrm{C}-\mathrm{ZnO}$ exhibited higher photocatalytic activities than $\mathrm{ZnO}$ NPs.
\end{abstract}

\section{Keywords}

ZnO Nanoparticles, Cotton Loaded with Zno, Methylene Blue, Photocatalytic Activity

\section{Introduction}

$\mathrm{ZnO}$ oxide is an important n-type semiconductor material which receives a great interest for various applications due to its unique properties, such as a direct wide band gap $(3.37 \mathrm{eV})$, large exciton binding energy $(60 \mathrm{meV})$ at room temperature [1]. $\mathrm{ZnO}$ is one of the most photocatalyst due to low cost, nontoxic, high catalytic activity, thermal stability and environmental friendly [2] [3] [4]. $\mathrm{ZnO}$ has received much attention as a very promising photocatalyst for photocatalytic degradation of water pollutants, because it produces $\mathrm{H}_{2} \mathrm{O}_{2}$ more efficiently, it absorbs high efficiency with solar light and has higher rates of activities [5]. There are some routes used to improve the photocatalytic performance 
of $\mathrm{ZnO}$, such as doping metal or non-metal ions likes $\mathrm{Mg}, \mathrm{C} \mathrm{Al}$ and graphite [6] [7] [8] [9], and combining $\mathrm{ZnO}$ with another semiconductor materials such as $\mathrm{Tio}_{2}$ [10] [11] [12]. It is very important to separate traditional catalysts from reaction systems. So we can use cotton fibers as supporting material. Cotton fibers have characterized by good moisture absorptivity, self-cleaning, high catalytic efficiency, low cost, easy recycling, and environmental sustainability [13]. In the present work, $\mathrm{ZnO} \mathrm{NPs}$ are successfully synthesized by co-precipitation technique. The structural and optical properties of the ZnO NPs were investigated. Also, the photocatalytic activities of $\mathrm{ZnO} \mathrm{NPs}$ and cotton loaded with $\mathrm{ZnO}$ for the degradation of $\mathrm{MB}$ under visible light and UV lamp were studied.

\section{Experimental Work}

\subsection{Synthesis}

Co-precipitation technique is suitable and a low-cost method for preparing $\mathrm{ZnO}$ NPs with a semispherical shape. $\mathrm{ZnSO}_{4}$ and $\mathrm{NaOH}$ solution were prepared separately and then mixed together. The solution was maintained at room temperature stirring for $2 \mathrm{~h}$ and heating of $\mathrm{Zn}(\mathrm{OH})_{2}$ at $70^{\circ} \mathrm{C}$ for $24 \mathrm{~h}$ for drying. The dried ingots were heated at $400^{\circ} \mathrm{C}$ for $4 \mathrm{~h}$, after that time period, the powder was left to cool down slowly at room temperature to get pure $\mathrm{ZnO}$.

The preparation of $\mathrm{C}-\mathrm{ZnO}$ as follows, cotton fibers were washed several times with deionized water. Then clean it by acetone and ethanol, and let dried at room temperature for $24 \mathrm{~h}$. Then the cotton fibers were immersed in the $\mathrm{ZnO}$ solution on stirrer for $1 \mathrm{~h}$. The solution was filtrated, and dried the cotton fibers at $150^{\circ} \mathrm{C}$ for $2 \mathrm{~h}$. During this step, $\mathrm{ZnO}$ NPs were loaded on the cotton fiber.

\subsection{Photocatalytic}

The photocatalytic properties of $\mathrm{ZnO} \mathrm{NPs}$ and $\mathrm{C}-\mathrm{ZnO}$ were measured through the photo-degradation of $\mathrm{MB}$ dye under the direct sunlight and under the Philips $400 \mathrm{~W}$ lamp illumination. The experiments were carried out as follows: Solution of $10 \mathrm{ppm} \mathrm{MB}$ dye was prepared, then we have four beakers divided into two categories one for sunlight and the second for lamp illumination. Each beaker contains $100 \mathrm{ml}$ of the dye. For each group, two photocatalytic were used for comparison, $0.1 \mathrm{~g}$ of $\mathrm{ZnO}$ nanoparticles and 0.4 gram of $\mathrm{C}-\mathrm{ZnO}$. UV-vis absorption was used to evaluate the photocatalytic degradation for $\mathrm{MB}$ dye.

\subsection{Characterization Techniques}

The obtained $\mathrm{ZnO}$ powder was characterized by X-ray diffraction (XRD), analysis of the samples was performed using a Rigaku miniflex diffractometer with CuKa radiation $(\lambda=1.5406 \AA$ ). Scanning electron microscopy (SEM; Inspect $S$, FEI, Holland) was used to determine the particle size and morphology of the prepared sample. Optical characterization was carried out using a Shimadzu UV-3600 UV-VIS-NIR spectrophotometer in the wavelength range $200-850$ $\mathrm{nm}$. 


\section{Results and Discussions}

\subsection{Characterization}

XRD pattern of the pure $\mathrm{ZnO}$ exhibits a hexagonal wurtzite structure with a preferred (101) orientation as shown in Figure 1. The diffraction peaks corresponding to (100) and (002) planes of $\mathrm{ZnO}$ a hexagonal phase were also observed. Average crystalline size (D) is found to be $\sim 29 \mathrm{~nm}$ by using Debye-Scherrer's equation $(D=0.94 \lambda / \beta \cos \theta)$ [14] [15], where $\lambda$ is wavelength of $\mathrm{X}$-rays, $\beta$ is full width at half maximum (FWHM) and $\theta$ is the diffraction angle.

The morphology of $\mathrm{ZnO}$ NPs, cotton fibers and $\mathrm{C}-\mathrm{ZnO}$ were studied from SEM. Figure 2(a) shows the presence of $\mathrm{ZnO}$ sample in a spherical shape with average particle size $\sim 29 \mathrm{~nm}$. A smooth surface for the cotton fibers with no particles on its surface is shown in Figure 2(b), while C-ZnO is shown in Figure 2 (c), its obvious differences, which were covered with a large quantity of $\mathrm{ZnO}$ NPs with a good dispersed. The stability of ZnO NPs on the surface of cotton fibers may be related to electrostatic bonding interactions between the negatively charged hydroxyl groups on cotton fiber and positively charged from the $\mathrm{ZnO}$ Nps.

The optical properties of the ZnO NPs were studied by UV-visible spectroscopy. The absorption spectra of ZnO NPs were shown in Figure 3. The sharp absorption edge is observed for the wavelength of about $376 \mathrm{~nm}$ in the absorption spectra which is characteristic of ZnO NPs. The optical band gap $\left(E_{g}\right)$ for ZnO NPs was evaluated using the Tauc's relation $\left(\alpha h v=B\left(h v-E_{g}\right)^{1 / 2}\right)^{[}[16]$

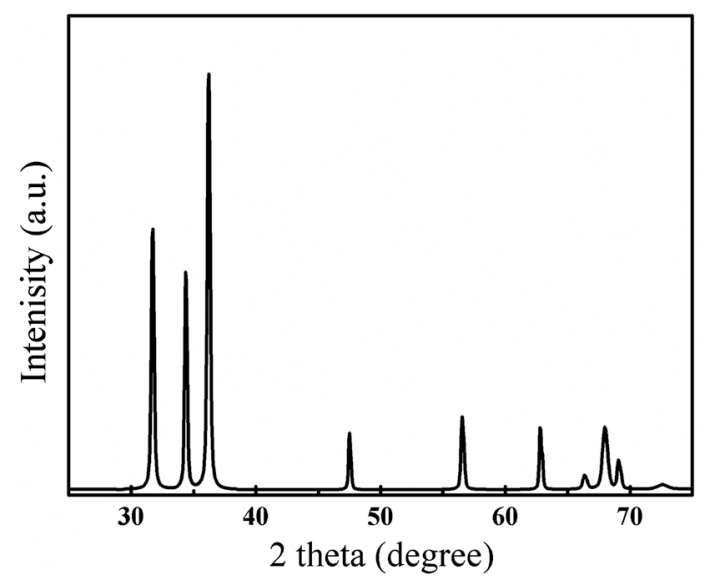

Figure 1. XRD diffraction patterns of $\mathrm{ZnO}$.
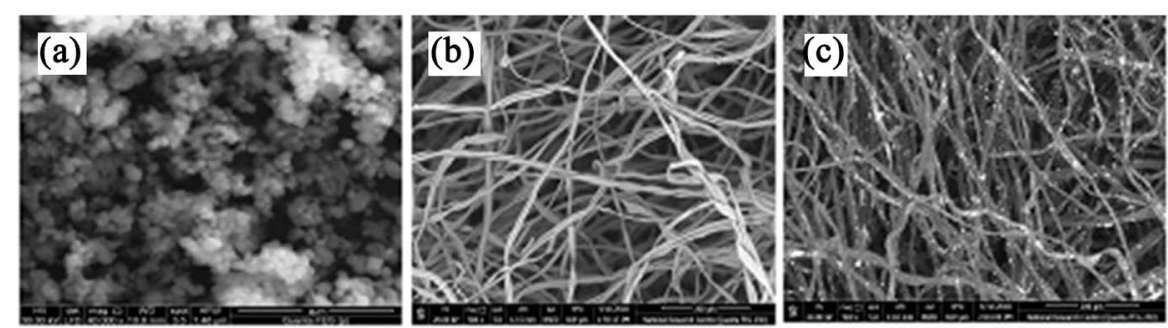

Figure 2. SEM image of (a) ZnO NPs, (b) cotton fibers and (c) C-ZnO. 


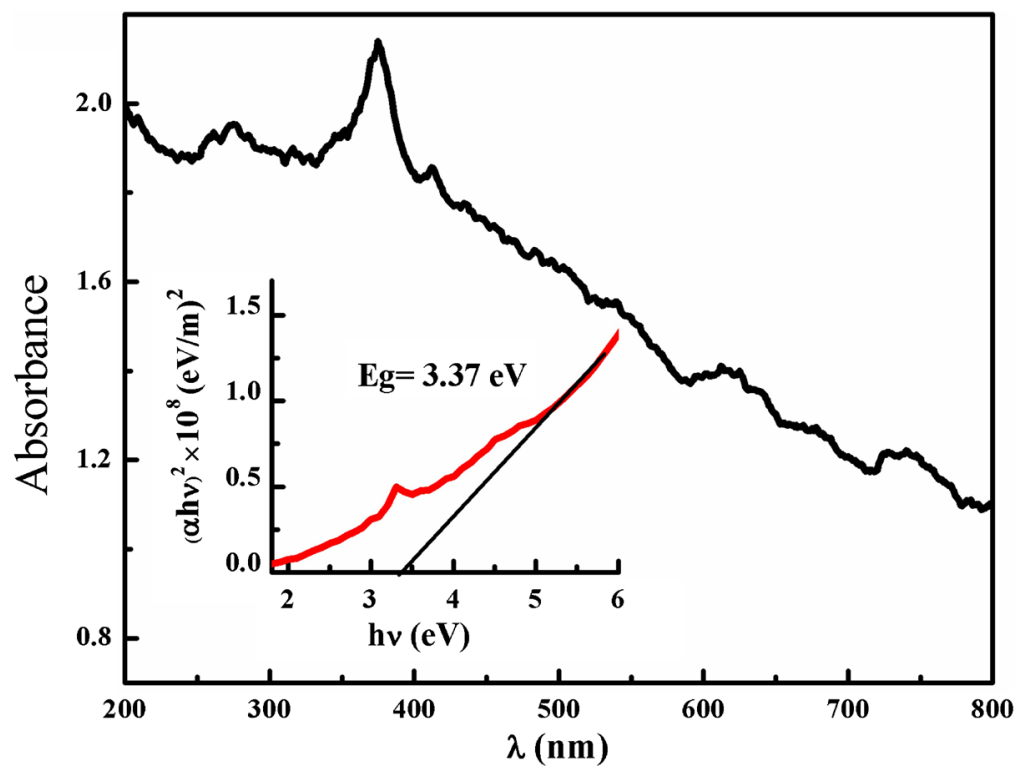

Figure 3. UV-Vis spectra of $\mathrm{ZnO}$ nanoparticles, and in the inset the bandgap calculation.

[17], where $\alpha$ is the absorption coefficient, $B$ is a constant and $h v$ is the photon energy. The optical band gap could be obtained by extrapolating the linear portion of the $(\alpha h v)^{2}$ versus $h v$ plot to $h v$ axis, as shown in the inset of Figure 3. The optical band gap was found to be $3.37 \mathrm{eV}$ for the $\mathrm{ZnO}$ NPs, which is very close to the intrinsic band gap of $\mathrm{ZnO}$.

\subsection{Photocatalytic Activity}

The percentage photocatalytic degradation was calculated by using the following equation:

$$
\begin{aligned}
\text { Percent of degradation } & =\left[\left(C_{0}-C\right) / C_{0}\right] \times 100 \\
& =\left[\left(A_{0}-A\right) / A_{0}\right] \times 100
\end{aligned}
$$

where, $C_{0}$ represents the initial concentration of the dyes, $C$ is the final concentration after illumination by UV light, $A_{0}$ is the initial absorbance, and $A$ is the variable absorbance [18].

In order to illustrate the potential application of $\mathrm{ZnO}$ NPs in wastewater treatment, we have investigated their photocatalytic activities for the degradation of MB under sunlight and $400 \mathrm{~W}$ UV lamp. Figures 4(a)-(d) show the absorbance spectra of the four systems at different degradation time. We show that with increasing degradation time, the intensity of the peaks decreases gradually, which indicates that MB is gradually photodegraded.

Under the UV-lamp irradiation for $2 \mathrm{~h}$, the photocatalytic efficiencies of $\mathrm{ZnO}$ NPs and $\mathrm{C}-\mathrm{ZnO}$ for $\mathrm{MB}$ are $62.2 \%$ and $73.8 \%$ respectively. In addition, the photocatalytic efficiencies of $\mathrm{ZnO}$ NPs and C-ZnO for MB under sunlight are $92.2 \%$ and $95.2 \%$ respectively. The results exhibit $\mathrm{C}-\mathrm{ZnO}$ can provide high performance of photocatalytic activity for the degradation of MB than ZnO NPs. Also, the photocatalytic for the degradation of $\mathrm{MB}$ was very efficient in the presence of 

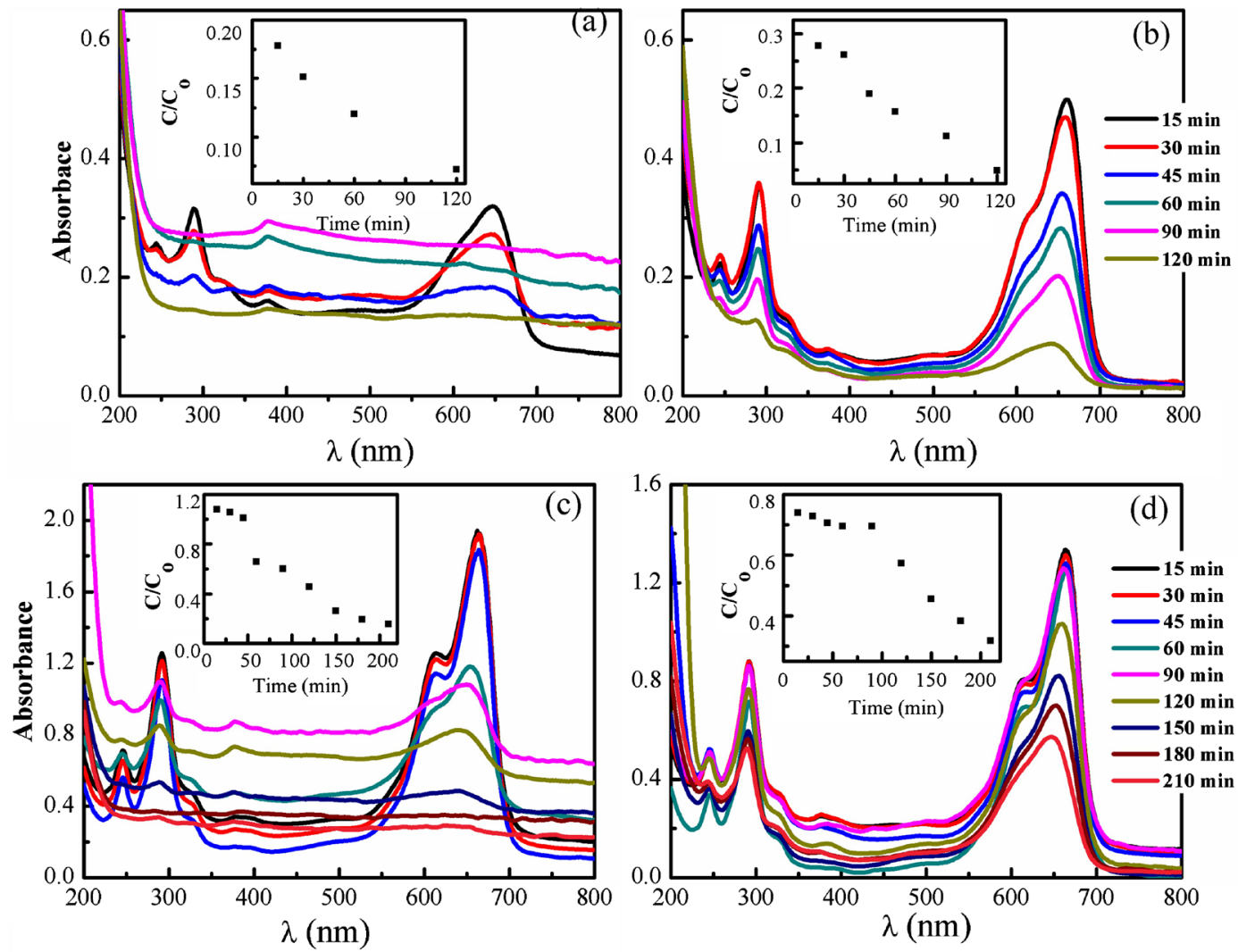

Figure 4. ((a), (b)) ZnO NPs and C-ZnO under sunlight, ((c), (d)) ZnO NPs and C-ZnO under UV, respectively.

sunlight more than the UV lamp.

The mechanism of photocatalytic activity of $\mathrm{C}-\mathrm{ZnO}$ as fellow: When the light energy is greater than or equal to the band gap energy, a high concentration of conduction band electrons $\left(\mathrm{e}^{-}\right)$and valence band holes $\left(\mathrm{h}^{+}\right)$are created in the density of ZnO NPs attached on cotton. Positive hole $\left(\mathrm{h}^{+}\right)$interacts with hydroxyl group $(-\mathrm{OH})$ on the cotton surface to produces hydroxyl radicals $(\bullet \mathrm{OH})$, which act as strong oxidants through the photocatalytic reaction. Moreover, photo generated electrons $\left(\mathrm{e}^{-}\right)$react with an electron acceptor, such as $\mathrm{O}_{2}$ and are adsorbed on the surface of the catalyst or dissolved in water to produce superoxide radical anions $\mathrm{O}_{2} \bullet$ and $\bullet \mathrm{HO}_{2}$. Free radicals react with each other, is major to formation of hydrogen peroxide and increasing gaseous oxygen in the photocatalytic reaction [19] [20] [21] [22]. All these react with methylene blue molecules for their full degradation.

\section{Conclusion}

Summarizing, we have prepared $\mathrm{ZnO}$ NPs and $\mathrm{C}-\mathrm{ZnO}$ by a simple process co-precipitation method. ZnO NPs were characterized by XRD, SEM and UVvisible. SEM images showed that spherical like ZnO NPs of average diameter 29 $\mathrm{nm}$ were successfully prepared. $\mathrm{ZnO}$ NPs were loaded on the cotton in a homogeneous manner. $\mathrm{ZnO} \mathrm{NPs}$ and $\mathrm{C}-\mathrm{ZnO}$ were used as photocatalytics for the re- 
moval of methylene blue dye from aqueous solutions under sunlight and a philips $400 \mathrm{~W}$ lamp. The results showed that $\mathrm{ZnO}$ nanoparticles decomposed MB by $92.22 \%$ in the sunlight and $62.22 \%$ in the lamp illumination, and $\mathrm{C}-\mathrm{ZnO}$ decomposes $95.27 \%$ of $\mathrm{MB}$ dye in the sunlight and $73.88 \%$ in the lamp illumination. In addition, $\mathrm{C}-\mathrm{ZnO}$ was high performance of photocatalytic activity for the degradation of $\mathrm{MB}$ than $\mathrm{ZnO}$ NPs.

\section{Conflicts of Interest}

The authors declare no conflicts of interest regarding the publication of this paper.

\section{References}

[1] Cho, S., Jang, J.W., Lee, J.S. and Lee, K.H. (2012) Porous ZnO-ZnSe Nanocomposites for Visible Light Photocatalysis. Nanoscale, 4, 2066-2071. https://doi.org/10.1039/c2nr11869f

[2] Pei, Z., Ding, L., Lu, M., Fan, Z., Weng, S., Hu, J. and Liu, P. (2014) Synergistic Effect in Polyaniline-Hybrid Defective $\mathrm{ZnO}$ with Enhanced Photocatalytic Activity and Stability. The Journal of Physical Chemistry C, 118, 9570-9577. https://doi.org/10.1021/jp5020143

[3] Chu, F.H., Huang, C.W., Hsin, C.L., Wang, C.W., Yu, S.Y., Yeh, P.H. and Wu, W.W. (2012) Well-Aligned ZnO Nanowires with Excellent Field Emission and Photocatalytic Properties. Nanoscale, 4, 1471-1475. https://doi.org/10.1039/C1NR10796H

[4] Lee, K.M., Lai, C.W., Ngai, K.S. and Juan, J.C. (2016) Recent Developments of Zinc Oxide Based Photocatalyst in Water Treatment Technology: A Review. Water Research, 88, 428-448. https://doi.org/10.1016/j.watres.2015.09.045

[5] Vignesh, K., Suganthi, A., Rajarajan, M. and Sara, S.A. (2012) Photocatalytic Activity of AgI Sensitized ZnO Nanoparticles under Visible Light Irradiation. Powder Technology, 224, 331-337. https://doi.org/10.1016/j.powtec.2012.03.015

[6] Qiu, X., Li, L., Zheng, J., Liu, J., Sun, X. and Li, G. (2008) Origin of the Enhanced Photocatalytic Activities of Semiconductors: A Case Study of $\mathrm{ZnO}$ Doped with $\mathrm{Mg}^{2+}$. The Journal of Physical Chemistry C, 112, 12242-12248. https://doi.org/10.1021/jp803129e

[7] Wang, Y., Shi, R., Lin, J. and Zhu, Y. (2011) Enhancement of Photocurrent and Photocatalytic Activity of ZnO Hybridized with Graphite-Like C3N4. Energy \& Environmental Science, 4, 2922-2929. https://doi.org/10.1039/c0ee00825g

[8] Sun, W.J., Li, J., Mele, G., Zhang, Z.Q. and Zhang, F.X. (2013) Enhanced Photocatalytic Degradation of Rhodamine B by Surface Modification of $\mathrm{ZnO}$ with Copper (II) Porphyrin under Both UV-Vis and Visible Light Irradiation. Journal of Molecular Catalysis A: Chemical, 366, 84-91. https://doi.org/10.1016/j.molcata.2012.09.010

[9] Lu, Y.H., Lin, W.H., Yang, C.Y., Chiu, Y.H., Pu, Y.C., Lee, M.H., Tseng, Y.C. and Hsu, Y.J. (2014) A Facile Green Antisolvent Approach to $\mathrm{Cu}^{2+}$-Doped $\mathrm{ZnO}$ Nanocrystals with Visible-Light-Responsive Photoactivities. Nanoscale, 6, 8796-8803. https://doi.org/10.1039/C4NR01607F

[10] Upadhyay, G.K., Rajput, J.K., Pathak, T.K., Kumar, V. and Purohit, L.P. (2019) Synthesis of $\mathrm{ZnO}: \mathrm{TiO}_{2}$ Nanocomposites for Photocatalyst Application in Visible Light. Vacuum, 160, 154-163. https://doi.org/10.1016/j.vacuum.2018.11.026 
[11] Yu, L., Chen, W., Li, D., Wang, J., Shao, Y., He, M., Wang, P. and Zheng, X. (2015) Inhibition of Photocorrosion and Photoactivity Enhancement for $\mathrm{ZnO}$ via Specific Hollow ZnO Core/ZnS Shell Structure. Applied Catalysis B: Environmental, 164, 453-461. https://doi.org/10.1016/j.apcatb.2014.09.055

[12] Khodami, Z. and Ejhieh, A.N. (2015) Investigation of Photocatalytic Effect of $\mathrm{ZnO}-\mathrm{SnO}_{2} / \mathrm{Nano}$ Clinoptilolite System in the Photodegradation of Aqueous Mixture of 4-Methylbenzoic Acid/2-Chloro-5-Nitrobenzoic Acid. Journal of Molecular Catalysis A: Chemical, 409, 59-68. https://doi.org/10.1016/j.molcata.2015.08.013

[13] Fan, Y., Zhou, J., Zhang, J., Lou, Y., Huang, Z., Ye, Y., Jia, L. and Tang, B. (2018) Photocatalysis and Self-Cleaning from g-C3N4 Coated Cotton Fabrics under Sunlight Irradiation. Chemical Physics Letters, 699, 146-154.

https://doi.org/10.1016/j.cplett.2018.03.048

[14] Cullity, B.D. (1978) Elements of X-Ray Diffraction. 2nd Edition, Wesley Publishing Company, Inc., Reading.

[15] Samb-Joshi, K.M., Sethi, Y.A., Ambalkar, A.A., Sonawane, H.B., Rasale, S.P., Panmand, R.P., Patil, R., Kale, B.B. and Chaskar, M.G. (2019) Lignin-Mediated Biosynthesis of $\mathrm{ZnO}$ and $\mathrm{TiO}_{2}$ Nanocomposites for Enhanced Antimicrobial Activity. Journal of Composites Science, 3, 90. https://doi.org/10.3390/jcs3030090

[16] Akbari, A., Mehrabian, M., Salimi, Z., Dalir, S. and Akbarpour, M. (2019) The Comparison of Antibacterial Activities of $\mathrm{CsPbBr} 3$ and $\mathrm{ZnO}$ Nanoparticles. International Nano Letters, 9, 349-353. https://doi.org/10.1007/s40089-019-0280-8

[17] Abdel-Baset, T.A., Fang, Y.W., Duan, C.G. and Abdel-Hafiez, M. (2016) Magnetic Properties of Chromium-Doped ZnO. Journal of Superconductivity and Novel Magnetism, 29, 1937-1942. https://doi.org/10.1007/s10948-016-3502-6

[18] An, D., Li, Y., Lian, X., Zou, Y. and Deng, G. (2014) Synthesis of Porous ZnO Structure for Gas Sensor and Photocatalytic Applications. Colloids and Surfaces A: Physicochemical and Engineering Aspects, 447, 81-87. https://doi.org/10.1016/j.colsurfa.2014.01.060

[19] Afzal, S., Daoud, W.A. and Langford, S.L. (2013) Photostable Self-Cleaning Cotton by a Copper(II) Porphyrin/TiO 2 Visible-Light Photocatalytic System. ACS Applied Materials \& Interfaces, 5, 4753-4759. https://doi.org/10.1021/am400002k

[20] Zhang, L., Wan, J. and Hu, Z. (2017) Preparation and Photocatalytic Activity of $\mathrm{TiO}_{2}$-Wrapped Cotton Nanofiber Composite Catalysts. Bio Resources, 12, 6062-6081.

[21] Li, Y., Zhao, H. and Yang, M. (2017) $\mathrm{TiO}_{2}$ Nanoparticles Supported on PMMA Nanofibers for Photocatalytic Degradation of Methyl Orange. Journal of Colloid and Interface Science, 508, 500-507. https://doi.org/10.1016/j.jcis.2017.08.076

[22] Casanova, L.C., Perez, A.A. and Rodenas, M.L. (2018) Effect of the Preparation Method (Sol-Gel or Hydrothermal) and Conditions on the $\mathrm{TiO}_{2}$ Properties and Activity for Propene Oxidation. Materials, 11, 2227.

https://doi.org/10.3390/ma11112227 